\title{
The Phenomenon of Internet Addiction in Adolescents: Case of Albania
}

\section{Phd. Candidate Desara Agaj}

\author{
Faculty of Social Sciences, Albanian University; Email: desara_agaj@live.it
}

\section{Dr. Alketa Marku}

Faculty of Social Sciences, Albanian University; Email: kety2001it@yahoo.it

\author{
Doi:10.5901/ajis.2015.v4n3s1p122
}

\section{Abstract}

\begin{abstract}
Nowadays most of the youngest spend a considerable time in online communication or playing videogames in computer. Very often this can lead to an addiction to it. This is a new phenomenon in our country, but which is rapidly spreading. Aim. This study aim to give an overview about the phenomenon of internet addiction in Albania and also to examine if exist any relationship between internet addiction and contingencies of self - worth scale in adolescents. Method. The sample of the study consisted of 120 adolescents, aged 15-18, in the city of Tirana. The data was collected through the application of the "Internet Addiction Scale", Kimberly Young, which was composed of 20 question items, and The Contingencies of Self-Worth Scale (Crocker et al., 2003) that consists of 35 items equally distributed on the seven types of contingencies. The Obtained data are analyzed with SPSS software. Results. The results show that adolescents in Albania have relatively high levels of internet addiction and the internet addiction correlates positively with two contingencies of the Self Worth scale, specifically with appearance and approval from others. This study is a part of a doctoral thesis.
\end{abstract}

Keywords: Internet addiction, self-worth, adolescents, computer, Albania.

\section{Introduction}

The development and progress of technology have made the internet a very important tool in everyone's life, since it became accessible to the public in the ' 90 . We use internet in many areas of our life including education, communication, satisfaction, shopping, health, etc. (Yilmaz F., Yilmaz R., Teker N., Keser H., 2014) Sometimes this can be a source of risk, because the overuse of internet lead to an addiction to it.

The are a lot of definitions about internet addiction. Goldberg used the term "addictive disorder" based on the substance addiction of Diagnostic and Statistical Manual for mental disorder $4^{\text {th }}$ edition (DSM-IV) for the first time, and he refers to Internet addiction as "pathological computer use". Young also suggested Internet addiction diagnosis criteria, including obsessions with the Internet, tolerance, withdrawal symptoms, excessive computer use, lack of interes in other activities. (Park, Jae Woo; Park, Kee Hwan; Lee, In Jae; Kwon, Min; Kim, Dai Jim;, 2012). Excessive Internet users have been called Internet addicts, pathological Internet users, computer addicts, computer mediated communication addicts, and computer junkies. The term that has been most often used for problematic Internet use is - Internet addiction. (Young \& Abreu, 2011)

Kendal (1998) has defined Internet addiction as a kind of psychological addiction representing the need to be active all the time on the Internet. Besides, Griffiths (2000) has described Internet addiction as a kind of technology addiction and a behavioral addiction similar to a gambling habit. Shapira, Goldsmith, Keck, Khosla, Mcelroy et al. (2003) suggest that problematic Internet use to be conceptualized as an impulse control disorder. (Aydin \& Sari, 2011)

According to Shapira et al. 2000, Internet addiction leads to emotional, social and sexual function disorders, psychiatric disorders and anxiety. Caplan (2002) specified the variables related to problematic internet use as depression, loneliness, shyness and self-esteem. Some of the problems researchers associated with excessive Internet use include failure to manage time, a loss of sleep, skipped meals, social isolation, and poor performance at school (Watkins, 2009).

(Eldeleklioglu, J. Vural-Batik, M., 2013).. There are a lot of studies that speaks, especially about the link between internet addiction and self-esteem. Different authors says that adolescents with low self-esteem tend to spend more time in social networking sites than those with higher self-esteem. (Aydin \& Sari, 2011) 


\section{Research Question}

What is the relationship between internet addiction and contegencies of self-worth scale?

Objectives:

- To examine the level of Internet addiction among 15-18 years old Albanian high school students.

- Gender differences according the internet addiction.

- To explore if exists any relationship between internet addiction and contingencies of self worth scale among adolescents in our country.

\subsection{Research Methods}

\subsubsection{Procedure}

We used cluster method to recruit the participants from the population of high school students in 4 public high schools in the city of Tirana, Albania. 120 adolescent participated in this study, $49(40.8 \%)=$ male and $71(59.2 \%)=$ female, age 1518. We selected in casual way high schools from the list of schools from Tirana Regional Education Directorate (DAR), and then we use the method of clustering to select the classes in these high schools. Permission for participation of students was obtained from the director of each school and students voluntarily participated in research. Completion of the questionnaires was anonymous and there was a guarantee of confidentiality. The instruments were administered in the classrooms. All participants were told about purposes of the study.

\subsubsection{Instruments}

The data was gathered through Internet Addiction Test and Contingencies of Self-Worth Scale (CSW).

The Internet Addiction Test, developed by Dr. Kimberly Young, comprises 20 items rated in a five-point Likert scale (from 1 - not at all, to 5 - always), that measures mild, moderate and severe level of Internet Addiction. On the basis of the total score obtained on the test, the individual is placed into one of three categories: average online user (from 20 to 39) who has a full control of his or her usage; experiences occasional or frequent problems because of excessive Internet use (from 40 to 69); or has significant problems because of Internet use (from 70 to 100). The internal consistency of Internet Addiction Test is a $=0.913$.

On the other hand, The Contingencies of Self-Worth Scale (Crocker et al., 2003) consists of 35 items equally distributed on the seven types of contingencies. Seven contingencies include family support, competition, appearance, god's love, academic competence, virtue and approval from athers. The subjects are requested to evaluate each item using a 7-points Likert scale (from 1-strongly disagree to 7-strongly agree) In all scales of the CSW, higher scores indicate higher relevance of that particular contingency of self-worth. The internal consistency of CSW is $a=.818$

\subsubsection{Data Analysis}

First, the questionnaires were coded and then all the data were entered to Statistical Package for the Social Sciences (SPSS 20). Then, they were subjected to frequency and percentage analyses, and Pearson Correlation Analyze was used to examine the relationships between internet addiction and the contingencies of self - worth scale. Finally, multiple linear regression was used between internet addiction and two contigencies of self - worth scale, specifically with appearance and approval from others.

\section{Analyses Results}

In this study, participated 120 adolescents, 71 female and 49 male. So, the proportion of females $59.2 \%$ was larger than those of males $40.8 \%$.

\subsection{The Status of Internet Addiction}

Most adolescents, part of this study, 58 (48.3\%) were identified as average online users or mild addicted, which mean that they have control over the usage of internet. $40(33.3 \%)$ were classified as possible Internet abusers, with moderate 
level of addiction, who experience occasional or frequent problems in their lives about internet usage. 22 adolescents $(18.3 \%)$ resulted non addicted, so they score under the 20 point in the test of internet addiction scale. And also, the results of this study show us that there were no adolescents diagnosed as Internet abusers, this does it mean that no one of them was diagnosed with severe levels of internet addiction.

\subsection{Differences between males and females according to the level of internet addiction.}

In total there are 71 females that fill in the forms and 35 (49.3\%) of them are mild addicted, or average online users, which mean that they can have control over their internet usage, 21 (29.6\%) of them have moderate levels of internet addiction, classified as possible internet abusers, who experience occasional or frequent problems in their lives about internet usage and $15(21.1 \%)$ of them are non addicted to the internet. On the other hand, in total there are 49 males and $23(46.9 \%)$ of them are mild addicted, or average online users and they can have control over their internet usage, $19(38.8 \%)$ of them have moderate levels of internet addiction, classified as possible internet abusers, who experience occasional or frequent problems in their lives about internet usage, and $7(14.3 \%)$ of them are non addicted to the internet.

\subsection{Correlations among variables}

Internet addiction correlates positively with two contingencies of the Self Worth Scale, specifically with appearance $(\mathrm{r}=.306)$ and approval from others ( $\mathrm{r}=.373)$. The five others contigences of self - worth scale, family support, competition, god's love, academic competence and virtue do not correlate with internet addiction.

\subsection{Prediction of the variables}

In this study was used multiple linear regression analysis to predict wich of the variables explain better internet addiction. Approval from others and appearance are correlated with internet addiction. These two variables best predict internet addiction, Adj. $\mathrm{R}^{2}=.169$.

$16.9 \%$ of the total variance is explained by these two variables. This is statistically significant, $p<0.05$.

For approval from others $\beta=.225, t=1.989, p<0.05$, for a total variance $16.9 \%$ and for appearance $\beta=.302, t=2.767$, $p<0.05$, for a total variance $16.9 \%$

\section{Discussion}

From the total sample of this study $48.3 \%$ of the adolescents were identified as average online users or mild addicted, which mean that they have control over the usage of internet. They used internet in their everyday life for different things, but they can managed it. $33.3 \%$ of the adolescents were classified as possible Internet abusers, with moderate level of addiction, who experience occasional or frequent problems in their lives about internet usage. $18.3 \%$ adolescents resulted non addicted, so they scored less then 20 in the test of internet addiction scale, and no adolescents were diagnosed as Internet abusers, this does it mean that no one of them was diagnosed with severe levels of internet addiction, that can cause serious problems in their life. But is important to emphazise that most of the adolescents are classified as mild and moderate addicited and this can cause frequent problems in their life, and maybe being more internet addictive in their future. Internet addiction correlates positively with two contingencies of self-worth scale, with appearance and approval from others. This make sense because adolescent tend to care to much about their appearance. But, there is no correlation between internet addiction and the other contingencies of self-worth scale as family support, competition, god's love, academic competence and virtue. We used multiple linear regression analysis to predict wich of the variables explain better internet addiction. Approval from others and appearance are correlated with internet addiction. These two variables best predict internet addiction, $\mathrm{Adj} . \mathrm{R}^{2}=.169$.

$16.9 \%$ of the total variance is explained by these two variables. This is statistically significant, $p<0.05$.

For approval from others $\beta=.225, t=1.989, p<0.05$, for a total variance $16.9 \%$ and for appearance $\beta=.302, t=2.767$, $p<0.05$, for a total variance $16.9 \%$

This pilot study has its positive aspect and its limitations. The first positive aspect is that, this research give a good contribution in our country according to the situation of the phenomenon of internet addiction in the adolescents, because studies like this are very limited. And this because internet addiction is a new phenomenon in our country. But 
also, the study has its own limitations. First, the number of the subjects included in the study is to small and for this the cluster does not represent all population. In the final phase this study will be extanded and be more representative and results maybe differ.

\section{Conclusion}

In the end, based on the evidence of our study, we can say that internet addiction is a present phenomenon in our country and it seems growing very fast day by day in adolescents in Albania. Of course, this is related to many factors, and especially depended on individual characteristics of adolescents. Internet addiction correlates with two contingencies of the Self Worth scale, specifically with appearance and approval from others.

\section{References}

Eldeleklioglu, J. Vural-Batik, M. (2013). Predictive effects of academic achievement, internet use duration, loneliness and shynnes on internet addiction. H.U. Journal of Education, 141-152.

Aydin, B., \& Sari, S. V. (2011). Internet addiction among adolescents: the role of self - esteem . Procedia Social and Behavioral Sciences $15,3500-3505$.

Park, Jae Woo; Park, Kee Hwan; Lee, In Jae; Kwon, Min; Kim, Dai Jim;. (2012). Standardization Study of Internet Addiction Improvement Motivation Scale. 373-378.

Yilmaz F., Yilmaz R., Teker N., Keser H. (2014). Prediction of Internet Addiction of University Students Based on Various Variables. World Journal on Educational Technology, 75-87.

Young, K. S., \& Abreu, C. N. (2011). Internet Addiction. A handbook and guide to evaluation and treatment. New Yersey: John Wiley \& Sons.

Watkins S. C. (2009). The young and the digital. Boston, Massachusetts, Beacon Press, pg. 136. 